196
$12 \cdot 19 \cdot 7$
LA-6104-MS

informal Report

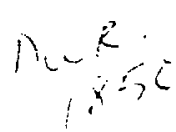

UC-78 and UC.34

Reporting Date: September 1975 Issued: November 1975

\title{
Numerical Calculation of Flashing from Long Pipes Using a Two-Field Model
}

by

\author{
William C. Rivard
}

Martin D. Torrey 
In the interest of prompt distribution, this report was not edited by the Technical Information staff.

This work was supported by the Nuclear Regulatory Commission, Division of Reactor Safety Research.

Priated in the United States of America. Available frome National Technical Information Service

US Department of Commerce

5285 Port Rloral Hoad Springtiold VA 2215!

Price: Printed Copy 4.00 Mieroliche $\$ 2.25$

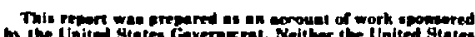

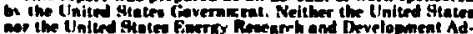

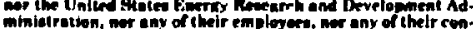

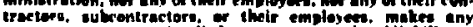

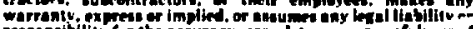

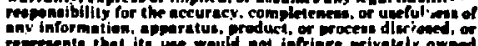

rements. 


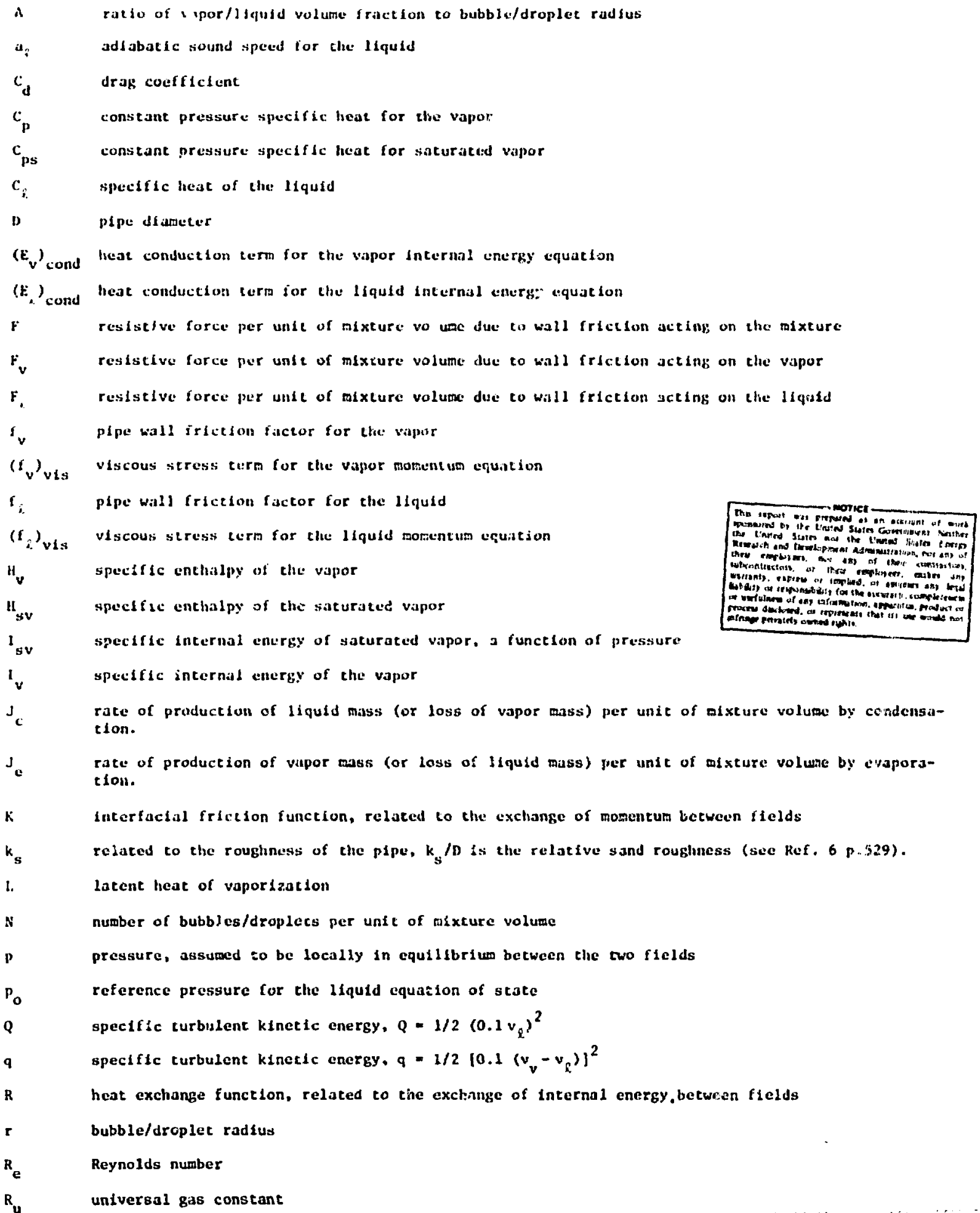


$T$ liquid Eeaperature

$\underline{u}$ vapor velocity, $u_{v}=$ radial ccmponent, $v_{v}$ - axial cueponent Lockhart-Hartinell parameter that relates to to tis function of pressure tased in the detortination of $C_{p}$ moleculaz diffusivity of the liquid 
NUMERICAL CN.CULATION OF F:ASHINC FROM LONC PIPES

ISINC A TWO-FIFLD MODEL.

by

Hilliat C. Rivard and Martin D. Torrey

ABSTECT

\begin{abstract}
A two-ficid aodel for twomptise flows, In which the vapor and IIquid phases have offferent densitles, velocities, and cemperatures, has been used to calculati the flashing of water roun long bipts. The inf (Implicie tultifleld) technlque is used en moneteally solve the transient equations that govern the dynates of each phise. The fluw physics is described w th flnte rate phatac transitions, ineterfactal friction, hear cratus fer, pipe dall frictlon, and appropriate stace equations. The resultsi of the calculat lons are tempared with medsured instorles of pressure, temperature, and void fraction. A paramoter study indlcates the relative sensletuity of the resules to che various plystial models that are used.
\end{abstract}

\section{Inthonuctios}

An accurite descrlption of the cransient dynamliss of culefdimensional two-phase flow is necessary In order to perfora an accuriste tallecy analysis for light water nuclear reactors. Such an analysts reguires the usage of large, highly copplex conputer codes. Several such codes have been developed eliroughout the councry under the ausples of the Nuelear Regulatory Comission (WRC). To cvaluate these codez, several Seindard Problems are betng assewbled by the kRC. fiach problem is to be computed with the varlous codes and the results cospared with measured data.

This repore describes comparlsons of culculated icsults using the Kachina ${ }^{1.2}$ cole with the data of Eduards ec al. 3 for Seandord Problem No. 1. The results of a parameter study show the relative importance of the vartous wodels used In the cods to describe the macroscopic effeces of microscople processes. The kachINA code describes two-phase flow using separate sets of field equations for each phase. The vapor and liquid phases have different densities, velocitles, and temperatures but rme same pressure. References 1 and 2 give a detalled discussion of the field equations and a description of the IMF (Ioplicit Muleififld) technique that is used for thelr numerlal solution. Emphasis here is on the varlous nodels that are used to deseribe the fldid physles of steum-water mixtures relevant to standard probles so. 1. Specifically, these are the following:

1. Equations of state for steam and water allowing for compressibility of the liquid.

2. Finfte rate phase transictons.

3. Finte rate lnterfuclal heat sansfer and friction.

4. Pipe wall friction.

The six field equations and the above models are described in Sec. Il.

Standard Problem No. 1 involves the flash boiling of water from a long plpe closed at one end and suddenly opuned to the atmosphere at the ocher by the rupture of a diaphragm. Initially the pipe is filled with water at a temperature of $515^{\circ} \mathrm{K}\left(467^{\circ} \mathrm{F}\right)$ and a pressure of 69.9 bars ( $1000 \mathrm{psig}$ ). The plpe is $410 \mathrm{~cm}(13.44 \mathrm{ft}$.$) long with a 7.32 \mathrm{~cm}(2.88 \mathrm{in.})$ 
Inside diameter.

Edwards et al. have made quantitative measurements of pressure histories at several axial locations along the pipe wall and measurements of vold fraction and temperature at a location $318.2 \mathrm{~cm}$ (10.44 ft.) from the open end. Comparisons of the calculater results with these measurewents are made in Sec. III. The agreement is generally good.

The calculations have been perfermed by treating the region inside the pipe as one dimensional. Boch one- and two-dimensional descriptions have been used for the region outside che pipe. No spectal conditions have been applied at the pipe exit. The solution inside the pipe is found to be inserisitive to the detail of the description outside the pipe. A parameter study indicates that the solution inside the pipe is sensitive to the pipe wall friction and insensitive to the phase change rate, the interfacial heat transfer (temperature differences between the phases), and the 1nterfacial friction (velocity differences between the phases).

\section{THE TWO-FIELD MODEL}

Separate sets of fleld equations are used for the Liquid and vapor to describu the two-phase fluid dynamics. The fleld equacions for the liquid are coupled to the field equations for the vapor through mass, womentum, and energy exchange and the assumption of pressure equilibrium.

\section{A. Field Equations}

The time-dependent, two-dimensional equations are as follows:

$\frac{\partial_{p}^{\prime}}{\partial t}+\underline{\nabla} \cdot\left(\rho_{v}^{\prime} \stackrel{u}{u}_{v}\right)=J_{e}-J_{c}$,

$\frac{\hat{j} \rho \underline{u}_{v}}{\partial \tau}+\nabla \cdot\left(\rho_{v}^{\prime} \underline{u}_{v} \underline{u}_{v}\right)=-0 \underline{\nabla} p+K\left(\underline{u}_{l}-\underline{u}_{v}\right)$

$$
+J_{e} \underline{u}_{\ell}-J_{c} \underline{u}_{v}+\left(f_{v}\right)_{v i s}
$$

$$
\begin{aligned}
\rho_{v}^{\prime} \frac{\partial I}{\partial t}+\rho_{v}^{\prime} \underline{u}_{v} \cdot \underline{\nabla} I_{v}= & -p \underline{\nabla} \cdot\left|\theta \underline{u}_{v}+(1-\theta) \underline{u}_{\ell}\right| \\
& +K\left(\underline{u}_{\ell}-\underline{u}_{v}\right)^{2} \\
& +\left(J_{e}-J_{c}\right) p\left(-\frac{1}{\rho_{v}}-\frac{1}{\rho_{\ell}}\right) \\
& +R\left(T_{\ell}-T_{v}\right)+\left(w_{v}\right)_{v i s}+\left(E_{v}\right)_{\text {cond }}
\end{aligned}
$$

$\rho_{v}^{\prime}=\rho_{v} \theta, \rho_{l}^{\prime}=\rho_{Q}(1-\theta)$,

$\frac{\partial \rho_{\ell}^{\prime}}{\partial t}+\underline{\nabla} \cdot\left(\rho_{\ell}^{\prime} \underline{u}_{\ell}\right)=\mathbf{J}_{c}-J_{e}$.

$\frac{\partial \rho_{\ell}^{\prime} \underline{u}_{l}}{\partial t}+\nabla \cdot\left(\rho_{\ell}^{\prime} \underline{u}_{\ell} \underline{u}_{l}\right)=-(1-\theta) \underline{\nabla} p+k\left(\underline{u}_{v}-u_{l}\right)$

$$
+J_{c} \ddot{u}_{v}-J_{e} \underline{u}_{\ell}+\left(f_{\ell}\right)_{v i s} \text {, }
$$

$\rho_{\ell}^{\prime} \frac{\partial I_{\ell}}{\partial t}+\rho_{\ell}^{\prime} \underline{u}_{\ell} \cdot \underline{\nabla} I_{\ell}=-\left(J_{e}-J_{c}\right)$

$$
\begin{aligned}
& {\left[P\left(\frac{1}{p_{v}}-\frac{1}{p_{\ell}}\right)+I_{v}-I_{\ell}\right]} \\
& +R\left(r_{v}-T_{\ell}\right)+\left(w_{\ell}\right)_{v I s}+\left(E_{\ell}\right)_{\text {cond }} .
\end{aligned}
$$

The source terms containing $J_{e}$ and $J_{c}$ that appear in these equations model the mass, momentum, and energy transfers assoclated with phase change. The cerms associated with evaporation involve $J_{e}$ and those associated with condensation involve $J_{c} \cdot{ }^{\cdot}$ In the mass conservation equations, Eqs. (2.1) and (2.j), evaporation produces vapor mass at the expense of liquid mass while condensation does the reverse. The mass exchange produces a momentum transfer between the phases according to Eqs. (2.L) and (2.6). The 1iquid momentum decreases upon evaporation at the rate $\mathrm{J}_{\mathrm{e}} \underline{u}_{\ell}$ while the vapor momentum increases at 
this rate. Condensation, on the other hand, decreases the vapor momentum and increases the liquid momentum at the rate $J_{c} \underline{u}_{v}$. The specific internal energy of the vapor in Eq. (2.3) increases durfing evaporation as newly created vapor expands and compresses surrounding vapor. The specific internal energy of the liquid in Eq. (2.7) decreases durfing evaporation proportionally to the enthalpy difference between the vapor and liquid, which is the latent heat of evaporation for bo:ling between saturated states. During condensation the reverse effects occur.

These simple models are known to neglect many elements of the highly complex microphysics of phase change. For example, the whole process of momentum mixing and $i$ ts associated energy dissipation is neglected. Also, no distinction is made between the thermodynamic state of newly created vapor and the state of the surrounding vapor or the state of newly condensed liquid and that of the surrounding liquid. The relative importance of the varlous micruscopic processes must be determined through numerous careful calculations and comparisons with experimental data. It is our intention to develop the simplest possible models that adequately describe the essential physics related to the applications of interest. B. Equations of state

The pressure $p$ is related to the specific internal entrgy of the vapor $I_{v}$ and the microscopic vaper density $D_{v}$ for void fractions above a specifled minimum vaiue $\theta_{0^{\circ}}$ When $\theta \leqslant \theta_{0}$ the mixture is treated as a compressible liquid, which is discussed later. For $\theta>\theta_{0}$ the temperature of the vapor $T_{V}$ is determined from $\rho_{v}$ and $I_{v}$ while the temperature $T_{\ell}$ and the microscopic densicy $\rho_{\ell}$ of the 11quid are determined from $I_{\ell}$ neglecting the small effects of pressure on the liquid state. Specifically, for $\theta>\theta_{0}$ the vapor equation of state relation is

$\rho=\rho_{v}\left\{\left(\gamma_{s v}-1\right) I_{s v}-(\gamma-1)\left(I_{s v}-I_{v}\right)\right]$,

where $\gamma_{s v}(p)$ and $I_{s v}(p)$ are obtalned from analytic fits to data for saturated steam. These fits are given in the Append $1 x$. The vapor temperature is determined from the constant pressure spectfic heat relation
$H_{v}-H_{s v}=\int_{T_{s}}^{T_{p}}{ }^{T} c_{p}\left(T_{v}, p\right) d T_{v}$,

where $H_{s v}(p)=\gamma_{s v} I_{s v}, T_{s}(p)$ is the saturation temperature at the pressure $p$ given in the Appendix, and $C_{p}$ is given by

$C_{p}\left(T_{v}, p\right)=\frac{\gamma R_{u}}{2(\gamma-1)}\left\{1+R_{u} T_{v}\left[\left(R_{u} T_{v}\right)^{2}-\left.4 \alpha p\right|^{-\frac{1}{2}}\right\}\right.$.

The quantity $\alpha$ depends upon the pressure alone, 1.e.,

$\alpha(p)=\left(R_{u} T_{s}\right)^{2}\left\{1-\left|2(\gamma-1) c_{p s}\right| \gamma_{u}-\left.1\right|^{-2}\right\} / 4 p$,

where $C_{p s}$ is the cons ant pressure specific heat of the saturated vapor given in the Appendix. Solution of Eq. (2.9) gives the vapor temperature directly as a function of $\mathrm{p}$ and $\mathrm{H}_{v}$ as

$T_{v}=\frac{T}{2}+2 u p / T R_{u}$

where

$\tau\left(H_{v}, p\right)=\frac{2(\gamma-1)}{\gamma R_{u}}\left(H_{v}-H_{s v}\right)+T_{s}+\left(T_{s}^{2}-4 a p / R_{u}^{2}\right)^{\frac{1}{2}}$.

The liquid temperature and microscoplc density are determined from $I_{\rho}$ through analytic fits co the water data, which are given in the Appendix.

For non-equilibrium vapor, 1.e., vapor for which $\mathrm{T}_{\mathrm{v}}<\mathrm{T}_{\mathrm{s}}$, Eqs. (2.8) and (2.12) do not apply. In this case the following relations are used to determine $p$ and $T_{v}$

$P=\rho_{v}\left(\gamma_{s v}-1\right) I_{v}$,

$T_{v}=T_{S}+\left(H_{v}-H_{S v}\right) / C_{p s}$. 
These relations and Eqs. (2.8) and (2.12) are identical for saturated vapor.

When $\theta<\theta_{0}$, the mixture is treated as a compressible liquid with a high interfacial heat transfer rate and interfacial friction. The pressure is rels ed to the microscopic liquid density* as

$p=p_{0}+a_{\ell}^{2}\left(\rho_{\ell}-\rho_{\ell 0}\right)$

where $p_{0}$ and $p_{\ell_{0}}$ are reference values and $a_{\ell}$ is the adiabatic sound speed for the liquid (see the Appen$d f x)$. In accord with the high interfacial heat transfer rate the vapor temperature is set equal to the liquid temperature, which is decermined from $l_{\ell}$. The pressure and vapor temperature determine $I_{v}$ and $p_{v}$ from the vapor equation of state. This procedure ensures that $p$ is continuous across $\theta_{0}$. In accord with high interfacial friction, the vapor velocity is set equal to the liquid jelocity when $\theta<0_{0}$.

\section{Phase Change Rates}

The mass exchange between the vapor and liquid is governed by the evaporation and condensation rates $J_{e}$ and $J_{c}$, respectively. These rates are determined by the following expressions

$$
\begin{aligned}
J_{e} & =\lambda_{e} \Lambda \rho_{Q}^{\prime \theta}\left(T_{s} R_{u}\right)^{\frac{1}{2}}\left(T_{\ell}-T_{s}\right) / T_{s}, \text { for } T_{\ell}>T_{s} \\
& =0 \text {, otherwise }
\end{aligned}
$$

$$
\begin{aligned}
J_{c} & =\lambda_{c} A D_{v}^{\prime}(1-G)\left(T_{s} R_{u}\right)^{\frac{1}{2}}\left(T_{s}-T_{v}\right) / T_{s} \text {, for } T_{v}<T_{s} \\
& =0 \text {, otherwise }
\end{aligned}
$$

where $A$ is proportional to the area of contact between the two phases per unit of mixture volume. For $N$ equal size spherical bubbles or droplet; per unit of volume, $A$ is given by

$\Lambda= \begin{cases}\theta^{2 / 3}(4 \pi N / 3)^{1 / 3}, & \theta \leqslant 1 / 2 \\ (1-\theta)^{2 / 3}(4 \pi N / 3)^{1 / 3}, & \theta>1 / 2 .\end{cases}$

* For application to Standard Problem No. $1, \mathrm{~T}_{\ell}$ is essentlally constant for $\theta \leqslant \theta_{0}$ so that the pressure depends only upon the density.
Equarions (2.17) and (2.16) assume that the rate of energy transfer by diffuston wirhin the liquid and vapor is large relative to the race of energy exchange from phase change. Ir, accord with this assumption, the bulk liquid and vapor temperatures are used to determine $J_{e}$ and $J_{c}$. A better model in which the vapor production rate is controlled by the diffusion of thermal energy from the bulk liquid to the bubble incerface is described and demonstrated in Sec. 111 .

\section{Interfactal Friction}

The momentum and energy exchange that results from the dynamic interactiun of the vapor and liquid phases is modeled through the interfacial friction function $k$ given by

$K=\frac{3}{8} \sigma\left|c_{d}\right| \underline{u}_{v}-\underline{u}_{\ell}\left|+\frac{12 v}{r}\right| \Lambda$.

wherc

$v=\tilde{N}_{v}^{\prime}+D_{q}^{\prime}$,

$v=\theta v_{v}+(1-\theta) v_{2}$.

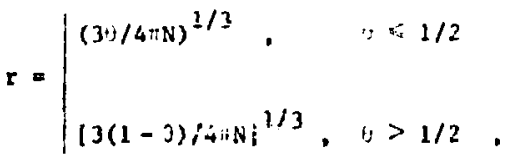

and $A$ is as defined in Eq. (2.19), In the liating cases of $0 \rightarrow 0$ and $0 \rightarrow 1$, Eq. (2.20) approximates the friction between phases as the drag on a single bubble/droplet times the number of bubble/droplets per unit of mixture volume.

\section{E. Heat Transfer}

The exchange of thermal energy between the vapor and liquid is modeled through the heat excharge function $R$. The functional dependence of $R$ upon fluid and thermodynamic variables is not restricted. The Influences of extreme vaiues of $R$ were investigated to deteraf ne its relative impertance for Standard Problem No. 1 . Constant values of $k$ large enough to produce equal cemperatures between the phases and small enough to create large temperature differences: $\left(65^{\circ} \mathrm{K}\right)$ were considered. 


\section{F. Pipe Wall Friccion}

For one-dimensional calculations of flashing from long pipes, it is necessary to model the effects of wall friction. The resistive forces per unit of wixture volume acting on the vapor and 11qu1d are

$F_{v}=-8\left(f_{v} P_{v} v_{v}^{2} \theta^{2} / 2 D\right) \theta_{v}^{2}$

and

$F_{Q}=-(1-\theta)\left[f_{Q} P_{Q} v_{Q}^{2}(1-\theta)^{2} / 2 D \mid \Phi_{l}{ }^{2}\right.$

respectively. These force terms enter the womentum equations, Eqs. (2.2) and (2.6), through the terms $\left(f_{v}\right)_{v i s}$ and $\left(f_{q}\right)_{v i s}$. The wultipliers $\phi_{v}^{2}$ and $\phi_{\ell}{ }^{2}$ are related through the Lockhart-Martinelli parameter $x$ as

$v^{2}=x *^{2}$

where

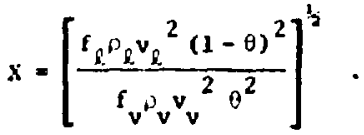

The friction factors $f_{v}$ and $f_{Q}$ depend upon the Reynolds number a:d the pipe roughness through the relation ${ }^{4}$

$f_{v, R^{-1}}=1.74-2 \log _{10}\left(2 k_{s} / D+18.7 f_{v, l}-\frac{k}{2} / R_{e}\right)$

where the Reynolds number is $R_{e}=\theta v_{v} D / v_{v}$ for the vapor and $R_{e}=(1-\theta) v_{\ell} D / v_{l}$ for the liquid. The model is completely defined when $\phi_{\ell}^{2}$ is specified. For the calculations described in the next section, two expresstons for $\phi_{Q}^{2}$ have been considered

$\Phi_{l}^{2}=\left(\rho / \rho_{l}\right)(1-\theta)^{2}$ and $\phi_{l}^{2}=(1-\theta)^{-2}$.
Adding Eqs. (2.24) and (2.25) we ctrain the resigtive force per unit of mixture volume acting on the twophase mixiure. This force is respectively •

$F=-\frac{f_{\ell} \rho v_{\ell}{ }^{2}}{2 D}$ and $F=-\frac{f_{\ell} \rho_{\ell} v_{\ell}{ }^{2}}{2 D}$

using the expressions for $\Phi_{\ell}^{2}$ in Eq. (2.29).

\section{NIMERICAL RESULTS}

The KACHINA code numerically solves the twofield model described in Sec. II. The numerical methodology used in KACHINA is described in deta11 In Refs. 1 and 2 . For the calculations reported here the 409.6-cw-long pipe is divided axially into 40 computational zones $10.24 \mathrm{~cm}$ in length. The sensicluity of the computational results to the nutber of zones in the pipe has been investigated by others witil the conclusior that 40 zones provide good spatial resolution. The region outside the pipe in the nelghborhood of the open end has been calculated in one and two dimenstons to assess the effects of exic conditions on the computed pressure histories within the plpe. Add1tional parameter studies include Investigations of phase change rates, Interfacial heat transfer, pipe wall friction, and interfacial friction.

The standard calculation is made with a single column of cells (one-dimenstonal everywhere), 40 cells Inside the pipe and 5 cells outside. Outside the plpe, phase change is not permitted. The calculation required about 9 minutes of computer time on the CDC-7600. The initial data are as follows:

1. Inside the pipe

$$
\begin{aligned}
& \text { a. } \mathrm{T}_{\mathrm{Q}}=\mathrm{I}_{\mathrm{V}}=502^{\circ} \mathrm{K}\left(444^{\circ} \mathrm{F}\right) \text { * } \\
& \text { b. } p=69.9 \text { bars (1000.psig) } \\
& \text { c. } t=0.0001 \\
& \text { d. } \rho_{v}=3.93 \times 10^{-2} \mathrm{~g} / \mathrm{cm}^{3}, \rho_{\ell}=0.831 \mathrm{~g} / \mathrm{cm}^{3} \\
& \text { e. } \underline{u}_{v}=\underline{u}_{l}=0 \\
& \text { f. } N=10 \text { bubbles per } \mathrm{nm}^{3} \\
& \text { 8. } c_{d}=0.5 \\
& \text { h. } k_{s} / D=1.0 \times 10^{-3} \text {, which is cypical for }
\end{aligned}
$$

*The measured initial temperature is $515^{\circ} \mathrm{K}$ according to Ref. 3. A new phase change model is described later that allows the calculations to begin at this temperature. 
i. The exit is fully open to flow, althougl Ref. 3 indicates a pericheral constriction was present that reduced the exit area by about $13 \%$.

2. Outside the pipe
a. $T_{\ell}=T_{v}=294^{\circ} \mathrm{K}\left(70^{\circ} \mathrm{F}\right)$, held fixed
b. $p=1.0$ bar $(14.7$ psia), held flxed
c. $\theta=0.9999$
d. $\rho_{v}=6.3 \times 10^{-4} \mathrm{~g} / \mathrm{cm}^{3}, \rho_{Q}=0.935 \mathrm{~g} / \mathrm{cm}^{3}$
e. $\underline{u}_{\mathrm{v}}=\underline{u}_{\mathrm{x}}=0$
f. $\mathrm{N}=10$ droplets per $\mathrm{cm}^{3}$.

The initial values of 6 and $N$ are arbitrary. specification of $\theta$ as smaller than 0.0001 or greater than 0.9999 has a negligible effect on the results. The value of $\mathrm{N}$ has been varied between 1 and 1000 . The effect of this variation on $K$ is small since $\nu$ is small and $r$ depends only on the cube root of $v$. The effect on the phase change rates is about a factor of 5 increase to $a$ factor of 2 decrease in their values, which effects the detalls of the early pressure histories but has negligible ef fect at late times. The value of $\theta_{0}$ is set at $\eta_{0}=0.008$.

the calculaced results are compared with measured pressure histories in Figs. 1a-1k. Comparisons with measured temperature and void fraction at scation 5 are made in Figs. $1 R-1 \mathrm{~m}$.

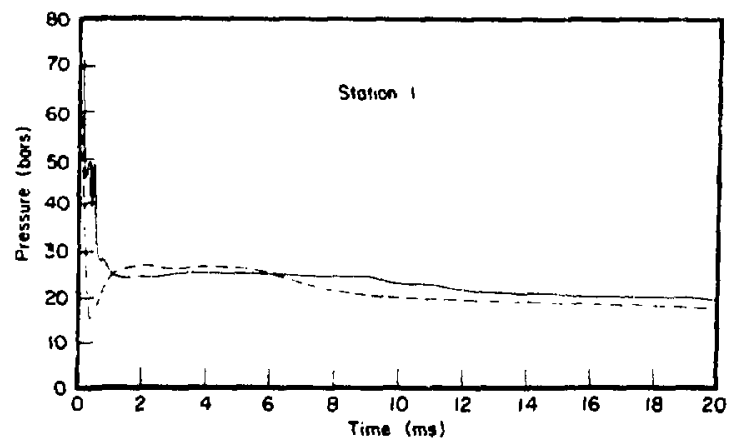

Fig. 1a. A comparison of KACHINA calculations (dashed line) with experimental data (solid Iine). Early time pressure history at Station $1,16.8 \mathrm{~cm}$ from the open end.

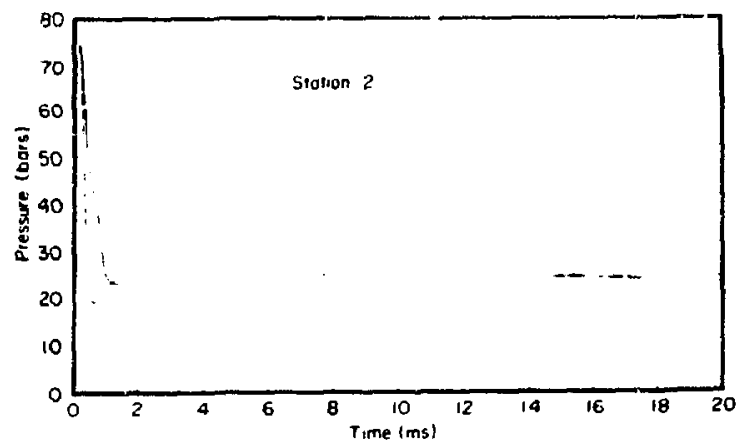

Fig. 1b. Early time pressure history at Station 2, $32.6 \mathrm{~cm}$ from the open and.

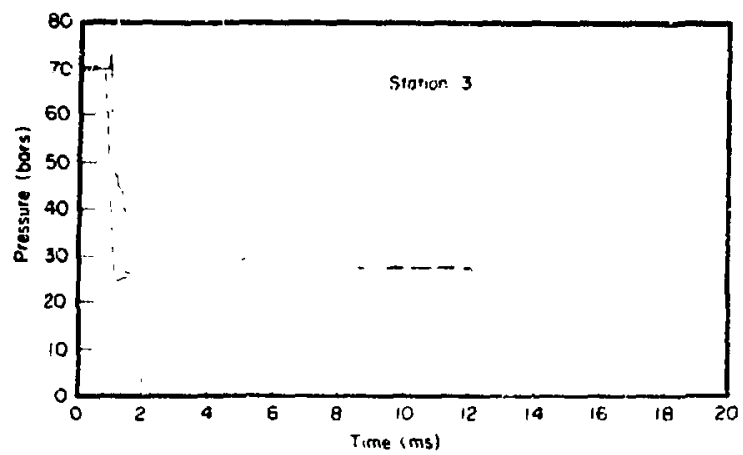

Fig. 1c. Early time pressure history at Station 3, $116.1 \mathrm{~cm}$ from the open end.

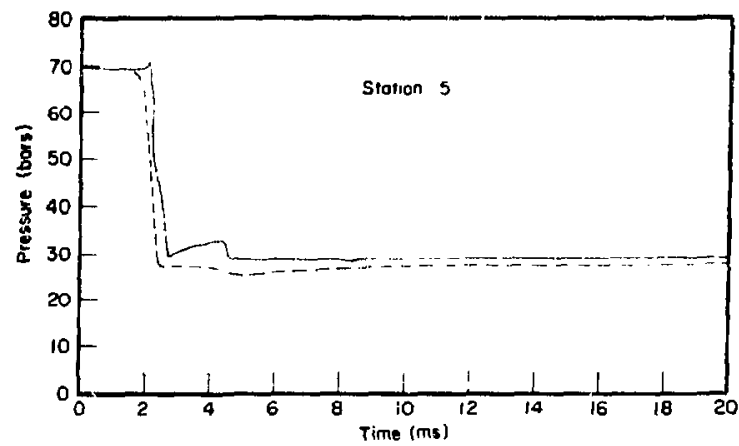

Fig. 1d. Early time pressure history at Station 5, $262.7 \mathrm{~cm}$ from the opten end. 

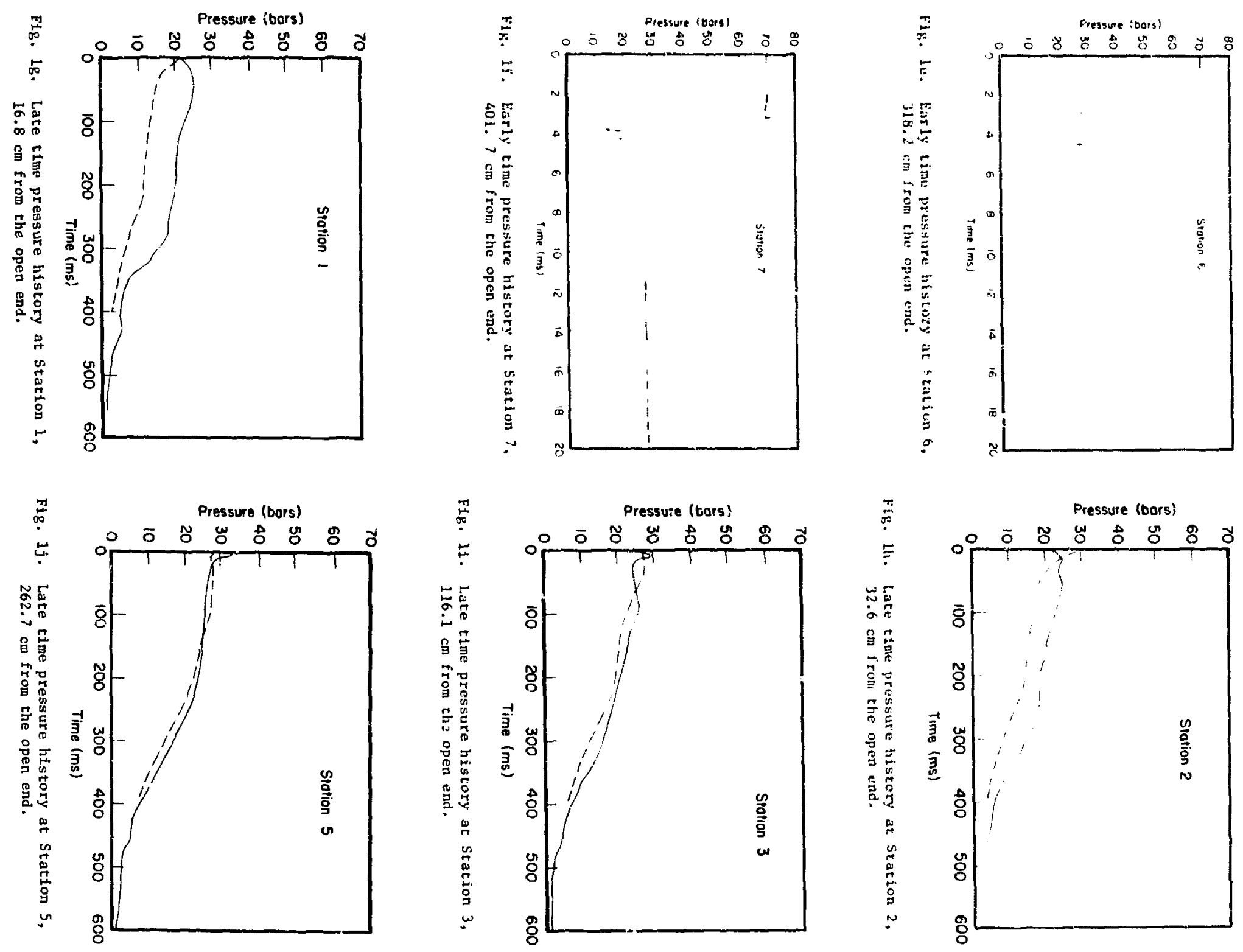


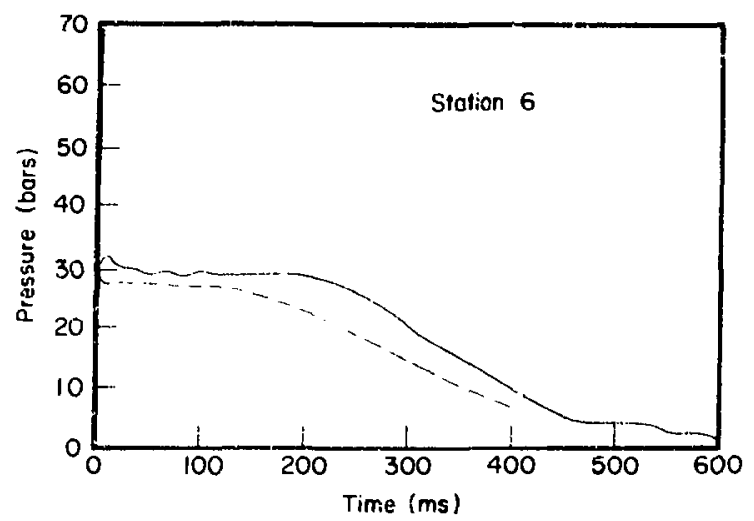

rig. 1k. Late time pressure histary at station 6 , $318.2 \mathrm{~cm}$ from the open el.d.

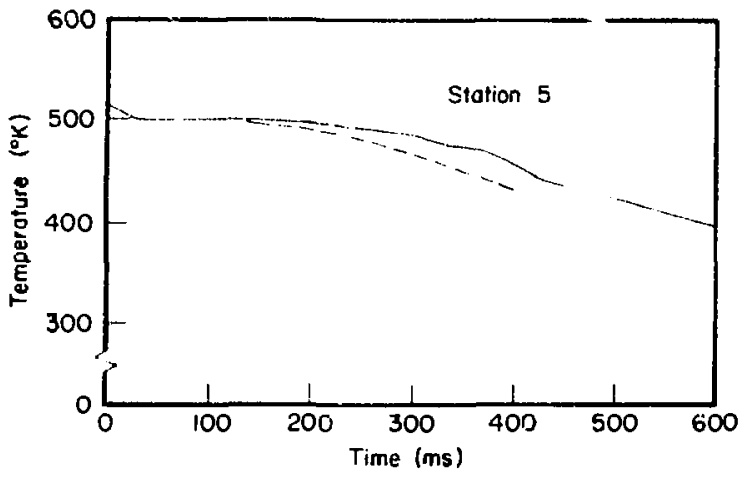

Fis. 1C. Temperature history at Station $5,262.7 \mathrm{~cm}$ from the open end.

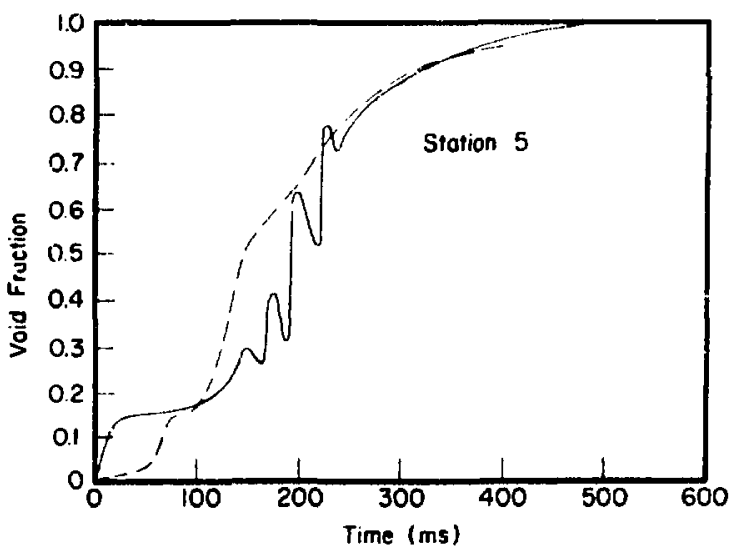

Fig. Im. Vold fraction history ac Station 5, 262.7 cri from the open end.
To assess the effect of the exit regton description on the pressure histories in the pipe, the full two-dimensional flow was ailculated outside the plpe. The velocity fields for the vapor and liquid are shown in Fig. 2 for the exit region and a portion of the regicn liside the pipe. The pressure histories that were obtained differed by less than 0.7 bars (10 psi) from those obtained witu the purely onedimensional standard calculation. For the two-dimensional calculation, the pressure was held fixed at 1.0 bar along the right and top boundaries of the exit region and phase change was pernited outside the pipe.

The phase change rate multipliers, $\lambda_{e}$ and $\lambda_{c}$, were chosen to approximate the early time pressure history at station 7 . Figure 3 shows the sensitiv1 ty of the calculated pressure histories at early time to variations in $\lambda_{e}$ and $\lambda_{c}$ over the range from 0.01 to 1. The value of 1.0 corresponds closely to an equilibrium phase cliange while the value of 0.01 gives a phase change rate that is clearly too slow

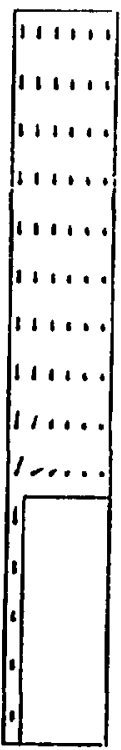

(a)

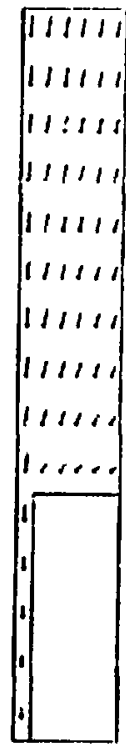

(b)
Fig. 2. Velocity vectors for the vapor (a) and 11quid (b) in the exit region and a portion of the pipe. The length of the velocity vectore is proportional to the speed. The maximum vapor velocicy is $23.9 \mathrm{~cm} / \mathrm{sec}$ and the maximum liquid velocfty is $16.4 \mathrm{~cm} / \mathrm{sec}$. 


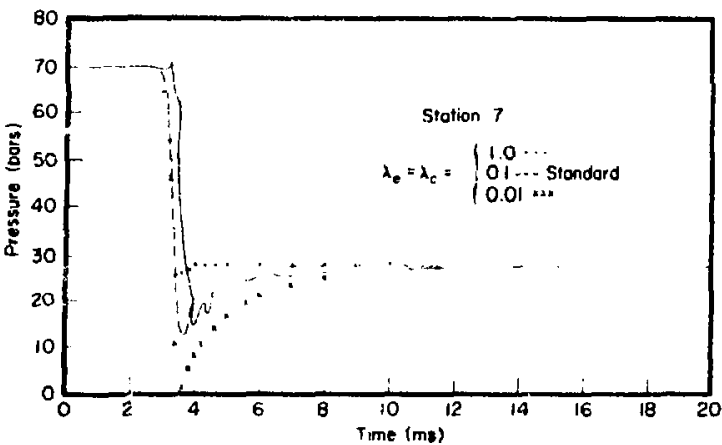

Fig. 3. Calculated early time pressure histories for varlous phase change rates compared to measured data (solid curve) at Station 7 , $401.7 \mathrm{~cm}$ from the open end.

to match the early time data. The value of 0.1 was used to obtain the results shown in Figs. 1a- Jm. The calculated pressure histories at late times differ by less than 0.7 bars $(10 \mathrm{ps} 1)$ for $\lambda_{e}$ and $\lambda_{c}$ between 0.01 and 1 .

The heat transfer rate between flelds was var. led to investigate the effects of unequal phase temperatures on the pressure historles. Differences in the vapor and liquid temperatures ranged from $2^{\circ} \mathrm{K}$ for large values of the heat transfer coeffictent $\left(R=10^{4}\right)$ to $65^{\circ} \mathrm{K}$ for small values $(R=1)$. The effects on the calculated pressure histories was les; than 0.7 bars. The results shown in Figs. 1a-1m correspond to $R=10^{4}$.

The effects on inturfactal friction were investigated by cousidering a range of values for the nomentum exchange function $k$. Calculations were performed for $K$ as given by kq. (2.20) and for a constant value of $K=10^{4}$. In the first case, vapor velontios of $2.4 \times 10^{4} \mathrm{~cm} / \mathrm{sec}$ and liquid velocities of $1.6 \times 10^{4} \mathrm{~cm} / \mathrm{sec}$ were produced near the open end at a time of $100 \mathrm{ins}$. For the constant $K=10^{4}$ the vipor and liquid velocities differed by less than $1.0 \mathrm{~cm} / \mathrm{sec}$ for the entire blowdown. The calculated pressure historles are shown in Fig. 4 for station 5. K was computed according to Eq. (2.20) to obtain the results presented in Figs. $1 \mathrm{a}-1 \mathrm{~m}$.

The pipe wall friction models had the largest influence on the calculated pressure histories.

The two models that were investigated are given in Eq. (2.29). The results are shown in Fig. 5 for Station 5 at lace time. The pressure historles show

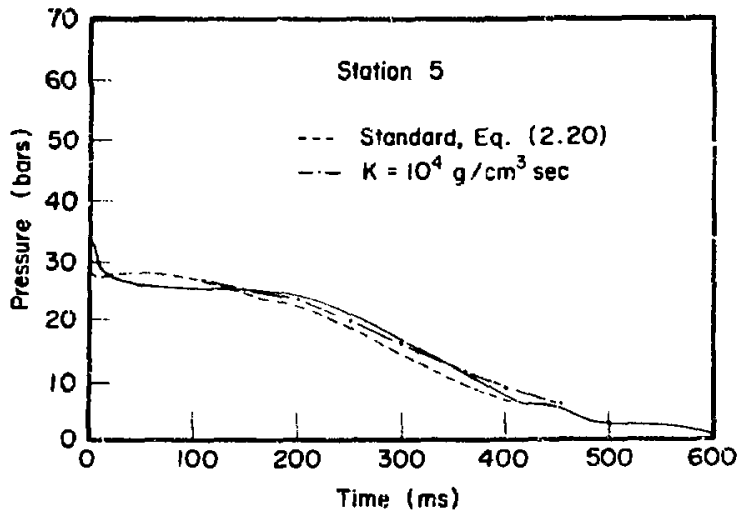

Fig. 4. Calculated late time pressure histories for two values of the interfacial friction coefficient compared to measured data (solid curve) at Scation 5. $262.7 \mathrm{~cm}$ from the open end. The vapor velocity is typically $50 \%$ higher than the 11quid velocily near the exit for the siandard calculation and essenthally the same as the liquid velocity for $\mathrm{K}=10^{4} \mathrm{~g} / \mathrm{cm}^{3}-\mathrm{sec}$.

negligible differences at early time. The results given in Figs. la- la were vitained with $\phi_{Q}^{2}=(1-\theta)^{-2}$. The results of the standard calculation differ most with the data near each end of the pipe. These differences are not sensitive to any of the param meter variations that have been considered and have also been noted for calculations performed with the SOLA-DF' code on this problem. A significant difference, which should not be overlooked at this point, is that the calculations have heen performed for an Initfal liquid temperature of $502^{\circ} \mathrm{K}$ racher

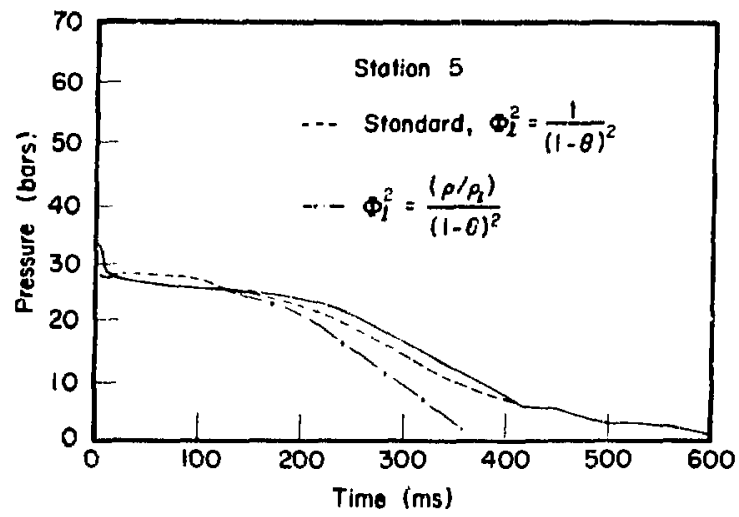

Fig. 5. Calculated late time pressure histories for two pipe wall friction models compared to measured data (solid curve) at Station 5 , $262.7 \mathrm{~cm}$ from the open end. 
than the measured value of $515^{\circ} \mathrm{K}$. When the calculations are performed for this higher initlal temperature the early time pressure histories approach 34.6 bars ( 502 psia), which corresponds to the saturation pressure at $515^{\circ} \mathrm{K}$ and is about 7 bars (100 psi) above the data. In Ref. 6 it is suggested that the liquid temperature at the bubble interface, rather than the bulk liquid temperature, controls the initial production of vapor. At later times when significant turbulence is generated it is postulated that the temperature difference between the interface and bulk liquid essentially vanishes and the bulk liquid temperature controls the boiling. Calculations performed in Ref. 6 with a model to represent this showed good agreement for the early tine pressure histories and significantly Improved the agreement at late time at Station 6 . No Improvement, however, was found near the open end of the pipe. This difierence is discounted in Ref. 6 by the fact that calculations for anuther pipe diameter agr:e well with data ntai the open end. Based on this demonstration the model certainly appears to have therit but suffers from the fact that it required an a priort knowledge of the $13^{\circ} \mathrm{K}$ temperature difference.

A model is proposed here that will predict this temperature difference as a natural consequence. This model is based on the well-known relation for the asymptotic growth of a small bubble when the growth is controlled by conduction of heat from the bulk liquid to the bubble interface. ${ }^{7}$ The asymptotic rate of bubble growth is given by

$\frac{d r}{d t}=\frac{6 \rho_{\ell} C_{l} k}{\pi r}\left(\frac{T_{l}-T_{E}}{\rho_{v} L}\right)^{2}$.

For simplicity at this stage of development, we neglect the intial inertia dominated growth associated with very small bubbles. The quantity $k$ is the effective thermal conductivity of the liquid. At early time it is the molecular conductivity. At late times it increases sharply as urbulence develops according to the relation

$\left.\kappa=k_{\ell}+k_{\ell} \mid 0.05 s(2 Q)^{\frac{1}{2}} / \alpha_{\ell}+0.005 r_{b}(2 q)^{\frac{1}{2}} / \alpha_{\ell}\right]$.
The two terms in the square bracker describe the effects of turbulence on the transfer of thermal energy. The term on the far right accounts specifically for the effect of relative velocity between the phases where the characteristic eddy size scales to the bubble radius and $q$ is the specific turbulent kinetic energy given by $q=1 / 2\left[0.1\left(v_{v}-v_{\ell}\right)\right]^{2}$. The other term accounts for the effects of turbulence in the absence of relative velocity where the scale $s$ is given by $S=D / 20$ and $Q=1 / 2\left(0.1 v_{l}\right)^{2}$. The constants 0.05 and 0.005 are enplrically determined relaxation rates.

With this model the rate of production of vapor density is

$\frac{\partial \rho_{v}^{\prime}}{\partial t}=\frac{18.0 C_{\ell} \hat{\theta} \rho_{\ell} k}{\pi \rho_{v}}\left(\frac{T_{\ell}-T_{s}}{r^{L}}\right)^{2}$.

The results of calculations are shown in Figs. 6a-6b for early time at Station 7 and for late time at Station 6, respectively. The agreement with the data lends support to the model, which now allows us to perform predictive calculations directly from the measured initial data. The rate give. by Eq. (3.3) shows a sensitivity to the initial bubble radius. Future research should hopefully allow us to bound some initial bubble radius from considerations of nucleating sites and the Initial, Inertia dominated, growth rate.

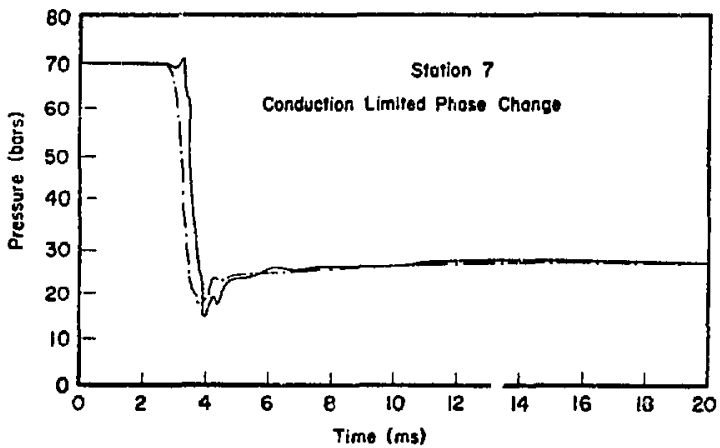

Fig. 6a. Calculated early time pressure history with the conduction limited phase change model compared with the measured data (solid curve) at Station $7,201.7 \mathrm{~cm}$ from the open end. 


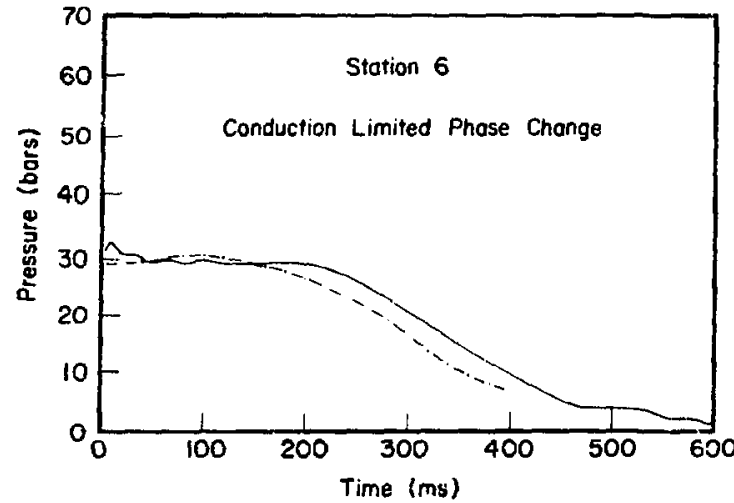

Fig. 6b. Calculated late time pressure history with the conduction limited phase change model compared to measured data (solld curve) at Station 6, $318.2 \mathrm{~cm}$ from the open end.

IV. SUMMARY

Two effects were investigated with the KAChINA. code that could not be investigated with the drift model used in Ref. 5, namely, large relative velocities and large temperature differences between the phases. The calculated results, however, were not sensitive tu either of these effects and hence the drift flux model and the two-fleld model gave essentially the same results. This should be expected fur this problem, since the onc-dimensional zones in the pipe necessarily result in mixture dynamics determined essentialiy by the liquid and only very slightly by the vapor. Furthermore, the pressure fleld is largeiy determined by the liquid temperature due to phase change so chat the vapor temperature and density are nearly inversely related. For problems where the phases are separated or where they dynamically interact and have much different temperatures, we would expect the two-field description to be superior to the drift model. In application to reactor safety analys is these situations are likely to arise, for example, in the downconer during emergency cooling.

APPENDIX

EQUUATION OF STATE FUNCTIONS AND PARAMETERS

The varfous functions and parameters thit are presently being used to describe the equations of state for steam and water are given here. These functions and parameters rplate to Eqs. (2.8)(2.16). The constants given are in $\left(\mathrm{g}-\mathrm{cm}-\mathrm{sec}-{ }^{\circ} \mathrm{K}\right)$ units with pressure in dynes $/ \mathrm{cm}^{2}$. Comparisons of calculatid state properties with steam table data are given in Tables A-I through A-III. Table A-I gives the comparisons for saturated steam, while Tables A-II and A-III give the results for superheated steam and subcooled water, respectively.

$\gamma_{s v}=\left\{\begin{array}{l}1.0666+1.02 \times 10^{-9} \mathrm{p}-2.548 \times 10^{-17} \mathrm{p}^{2}, \mathrm{p} \leqslant 2.0 \times 10^{7} \\ 1.0764+3.625 \times 10^{-11} \mathrm{p}-9.063 \times 10^{-19} \mathrm{p}, \mathrm{p}>2.0 \times 10^{7}\end{array}\right.$
$I_{\mathrm{sv}}=\mid \begin{aligned} & 2.6194 \times 10^{10}-4.995 \times 10^{15} /\left(3.403 \times 10^{6}+\mathrm{p}\right), \mathrm{p}<2.0 \times 10^{7} \\ & 2.5896 \times 10^{10}+6.35 \mathrm{p}-1.0583 \times 10^{-7} \mathrm{p}, \mathrm{p}>2.0 \times 10^{7}\end{aligned}$

$\gamma=1.30$ 


$$
\begin{aligned}
& T_{s}=117.8\left(10^{-6} \mathrm{p}\right)^{0.223}+255.2 \\
& c_{p s}=9.5875 \times 10^{6}\left(1.0-T_{B} / 647.3\right)^{-0.8566} \\
& v_{v}=0.2\left(10^{-6} p\right)^{-0.8426} \\
& P_{0}=6.992 \times 10^{7} \\
& \rho_{\ell 0}=0.831 \\
& a_{\ell}=1.234 \times 10^{5} \\
& v_{\ell}=\left\{\begin{array}{l}
2.950 \times 10^{-3}\left(10^{-6} \mathrm{p}\right)^{-0.2159,} \mathrm{p} \leqslant 1.5 \times 10^{7} \\
2.178 \times 10^{-3}\left(10^{-6} \mathrm{p}\right)^{-0.1038,} \mathrm{p}>1.5 \times 10^{7}
\end{array}\right. \\
& k_{l}=6.2 \times 10^{4} \\
& \mathrm{~T}_{\ell}=273.0+99.65\left(2.402 \times 10^{-10} \mathrm{I}_{\ell}\right)+0.4830\left(2.402 \times 10^{-10} \mathrm{I}_{\ell}\right)^{2} \\
& -0.4168\left(2.402 \times 10^{-10} I_{\ell}\right)^{3}+0.1183\left(2.402 \times 10^{-10} I_{\ell}\right)^{4} \\
& \nu_{\ell}=\left[1.1171-0.2789\left(2.402 \times 10^{-10} \mathrm{I}_{\ell}\right)+0.2895\left(2.402 \times 10^{-10} \mathrm{I}_{\ell}\right)^{2}\right. \\
& \left.-0.0994\left(2.402 \times 10^{-10} L_{\ell}\right)^{3}+0.0146\left(2.402 \times 10^{-10} I_{\ell}\right)^{4}\right]^{-1}
\end{aligned}
$$

\begin{tabular}{|c|c|c|c|c|c|c|}
\hline \multirow[t]{2}{*}{$P \times 10^{-6}$} & \multicolumn{2}{|c|}{$\mathrm{T}_{\mathrm{S}}$} & \multicolumn{2}{|c|}{$\mathrm{H}_{\mathrm{sv}} \times 10^{-10}$} & \multicolumn{2}{|c|}{$c_{p s} \times 10^{-7}$} \\
\hline & Calc. & Data & Calc. & Data & Calc. & Data \\
\hline 1.01 & 373.3 & 373.0 & 2.676 & 2.676 & 2.002 & 2.034 \\
\hline 4.76 & 422.0 & 423.0 & 2.740 & 2.745 & 2.368 & 2.320 \\
\hline 15.55 & 472.4 & 473.0 & 2.798 & 2.791 & 2.942 & 2.883 \\
\hline 39.78 & 523.0 & 523.0 & 2.797 & 2.800 & 3.942 & 3.918 \\
\hline 85.93 & 573.2 & 573.0 & 2.753 & 2.751 & 6.139 & 6.148 \\
\hline 165.35 & 623.2 & 623.0 & 2.544 & 2.568 & 16.065 & 15.8 \\
\hline
\end{tabular}

TABLE A-I

CONPARISON OF CALCULATED PROPERTIES WITH STEAM TABLE DATA FOR SATURATED STEAM 
TABLE A-II

COMPARISON OF CALCULATED PKOPERTJES WITH STEAM TABLE DATA IOR SUPERHEATE'D STEAM

\begin{tabular}{|c|c|c|c|c|c|}
\hline \multirow[t]{2}{*}{$\underline{P_{v}}$} & \multirow[t]{2}{*}{$\mathrm{I}_{\mathrm{v}} \times 10^{-10}$} & \multicolumn{2}{|c|}{$P \times 10^{-6}$} & \multicolumn{2}{|c|}{$\underline{T}$} \\
\hline & & Salc. & Data & Calc. & Data \\
\hline $5.16 \times 10^{-4}$ & 2.583 & 0.99 & 1.0 & 423.8 & 423.0 \\
\hline $3.48 \times 10^{-4}$ & 2.889 & 0.99 & 1.0 & 634.0 & 623.0 \\
\hline $4.30 \times 10^{-3}$ & 2.710 & 9.89 & 10.0 & 520.3 & 523.0 \\
\hline $3.03 \times 10^{-3}$ & 3.041 & 9.98 & 10.0 & 727.8 & 723.0 \\
\hline $1.93 \times 10^{-2}$ & 2.811 & 50.55 & 50.0 & 630.6 & 623.0 \\
\hline $1.36 \times 10^{-2}$ & 3.181 & 50.71 & So. 0 & 849.4 & 823.0 \\
\hline $4.46 \times 10^{-2}$ & 2.702 & 101.30 & 100.0 & 634.9 & 623.0 \\
\hline $2.81 \times 10^{-2}$ & 3.144 & 101.10 & 100.0 & 875.1 & 823.0 \\
\hline
\end{tabular}

TABLE A-III

COMPARISON OF CALCULATED PROPERTIES WITH STEAM TABLE DATA FOR SUBCOOLED WATER

\begin{tabular}{lcccc}
$I_{\ell} \times 10^{-10}$ & \multicolumn{2}{c}{$T_{\ell}$} & \multicolumn{2}{c}{$\underline{\rho_{\ell}}$} \\
& Calc. & Data & $\underline{\text { Calc. }}$ & $\underline{\text { Data }}$ \\
0.4178 & 373.2 & 373.0 & 0.9587 & 0.9599 \\
0.5445 & 403.6 & 403.0 & 0.9365 & 0.9366 \\
0.6731 & 434.4 & 433.0 & 0.9070 & 0.9093 \\
0.8042 & 465.9 & 463.0 & 0.8731 & 0.8780 \\
0.9393 & 498.6 & 493.0 & 0.8345 & 0.8419 \\
1.0808 & 533.0 & 523.0 & 0.7884 & 0.7992
\end{tabular}

\section{REFERENCES}

1. F. H. Harlow and A. A. Amsden, "Numerical Calculation of Multiphase Fluid Flow," J. Comp. Phys. 17. 19 (1975).

2. A. A. Amsden and F. H. Har low, "Kachima: An Eulerian Computer Program for Nuleifleld Fluid Flows," Los Alamos Scientific Laboratory report LA-5680 (1974).

3. A. R. Edwards and T. P. O'Brien, "Studies of Phenomena Connected with the Depressurization of hater Reactors," Jour. BNES q, 125 (1970).

4. II. Schlifting, Boundary Layer Theor: 4th Edttion, (McGraw-lli1l, New York, 1960).
5. T. A. Oliphant and $c$. h. Hirt, "Numerical Resolution Studies for Standard Problem One," concained in Los Alamos Scientific Laboratory report "Transport Tieory, Reactor Theory, and Reactor Safety" Li-6029-P?, Aprll I through June 30, 1975, ed. by K. D. Lathrop (August 1975).

6. $\therefore$ K. Hirt and N. C. Romero, "Application of a Drtfe Flux Nodel to Flashing in Straight Pipes," Los Alamos Scientific Laboratory report LA-S005-itS (1975).

7. J. 6. Collier, Convectrue Bolling and Condensation. (NeCraw-lli11, New York, 1972), pp.116-118. 